Contract No. and Disclaimer:

This manuscript has been authored by Savannah River Nuclear Solutions, LLC under Contract No. DE-AC09-08SR22470 with the U.S. Department of Energy. The United States Government retains and the publisher, by accepting this article for publication, acknowledges that the United States Government retains a non-exclusive, paid-up, irrevocable, worldwide license to publish or reproduce the published form of this work, or allow others to do so, for United States Government purposes. 


\title{
Ultraclean Fuels Production and Utilization for the Twenty-First Century: Advances towards Sustainable Transportation Fuels
}

\author{
${ }^{1}$ Elise B. Fox, ${ }^{2}$ Zhong-Wen Liu, and ${ }^{2}$ Zhao-Tie Liu \\ ${ }^{1}$ Savannah River National Laboratory, Aiken, SC 29808, USA \\ ${ }^{2}$ Key Laboratory of Applied Surface and Colloid Chemistry, School of Chemistry \& Chemical \\ Engineering, Shaanxi Normal University, Xi'an 710062, China
}

Ultraclean fuels production has become increasingly important as a method to help decrease emissions and allow the introduction of alternative feed stocks for transportation fuels. Established methods, such as Fischer-Tropsch, have seen a resurgence of interest as natural gas prices drop and existing petroleum resources require more intensive clean-up and purification to meet stringent environmental standards. This review covers some of the advances in deep desulfurization, synthesis gas conversion into fuels and feed stocks that were presented at the $245^{\text {th }}$ American Chemical Society Spring Annual Meeting in New Orleans, LA in the Division of Energy and Fuels symposium on "Ultraclean Fuels Production and Utilization”.

Key words: Ultraclean fuels; Fischer-Tropsch; Dimethyl ether; Higher alcohols; Carbon dioxide, desulfurization

\section{Introduction}

The cost-effective production and efficient utilization of energy and fuels has been the main stream driver for research and development in recent human history. Additionally, in the highly cultivated $21^{\text {st }}$ century, sustainable development is more deeply rooted in today's society helping to dictate a trend towards increased energy efficiency and cleaner fuel production and utilization. Thus, clean and sustainable energy and fuels are increasingly important and desirable. Where fuels are concerned, a significant portion of petroleum is consumed in the transportation sector, and the situation has been enhancing as a result of the continuing increase in vehicle numbers and miles throughout the world, 
especially in the developing countries such as China. Two important issues have emerged in recent years. The heavy dependence of transportation fuels on petroleum and the substantial content of sulfur contained in crude oil make $\mathrm{SO}_{\mathrm{x}}$, from combustion in vehicles, one of the worst emissions in air. As a result of environmental and health concerns over $\mathrm{SO}_{\mathrm{x}}$, increasingly stringent legislations are put on the reduction of sulfur in transportation fuels, ${ }^{1}$ and this has prompted new research into the deep desulfurization of petroleum feedstocks. ${ }^{2}$ On the other hand, because of its non-renewable nature, high consumption rates, and the limited reserves of petroleum, transportation fuels from non-petroleum resources have long been extensively explored. ${ }^{3-7}$ Among the available choices, the mixture of carbon monoxide and hydrogen (syngas) derived from other carbon-based resources such as coal, natural gas, and biomass has been proven a versatile platform for the synthesis of liquid fuels and high-value added chemicals. ${ }^{4-7}$

Changing environmental regulations in the U.S and abroad are also a major driving force for the production of ultraclean fuels. Petroleum accounts for 36\% of energy use in the U.S, 93\% of which is used for transportation. ${ }^{8}$ Increasing rates of personal vehicle ownership worldwide are proving to have a dramatic effect on the air quality locally and regionally. Some success has been achieved through the decrease in particulate matter, $\mathrm{SO}_{2}$, NOx, volatile organics, and $\mathrm{CO}$ and lead as can be seen in Table 1. However, $\mathrm{NH}_{3}$ and $\mathrm{CO}_{2}$ are rising. The dramatic rise in $\mathrm{CO}_{2}$ emissions from vehicles are a cause for concern which must be addressed through a mixture of increased engine efficiency, cleaner burning fuels, and alternative fuel development. According to the U.S. Energy Information Agency, current U.S. natural gas reserves out number petroleum reserves $13: 1^{9}$. The petroleum reserves are also dirtier and require more and more expensive downstream refining to meet more stringent environment requirements. This makes the production of liquid fuels and feed stocks for chemicals by natural gas processing more commercially attractive.

Table 1. Change in vehicle emissions from 1990 to 2008 in thousands of tons. Data from ${ }^{10-11}$.

\begin{tabular}{|l|l|l|l|l|l|l|l|l|l|}
\hline Source & $\mathbf{P M}_{2.5}$ & $\mathbf{P M}_{\mathbf{1 0}}$ & $\mathbf{N H}_{\mathbf{3}}$ & $\mathbf{S O}_{\mathbf{2}}$ & $\mathbf{N O}_{\mathbf{x}}$ & VOC & $\mathbf{C O}$ & ${ }^{*} \mathbf{C O}_{2}$ & Pb \\
\hline Highway & -213 & -216 & +153 & -439 & $-4,386$ & $-5,970$ & $-71,389$ & $+333,900$ & -0.42 \\
\hline Non-road & -17 & -24 & -28 & +85 & +474 & -76 & -3411 & & -0.27 \\
\hline
\end{tabular}


The need for deep desulfurization of petroleum feed stocks, changing environmental regulations, an increase in proven natural gas reserves, and improved process efficiencies have led to the emergence and quick development of ultraclean fuels. This is clearly reflected from the increased publication activity on clean fuel topics as given in Figure 1.

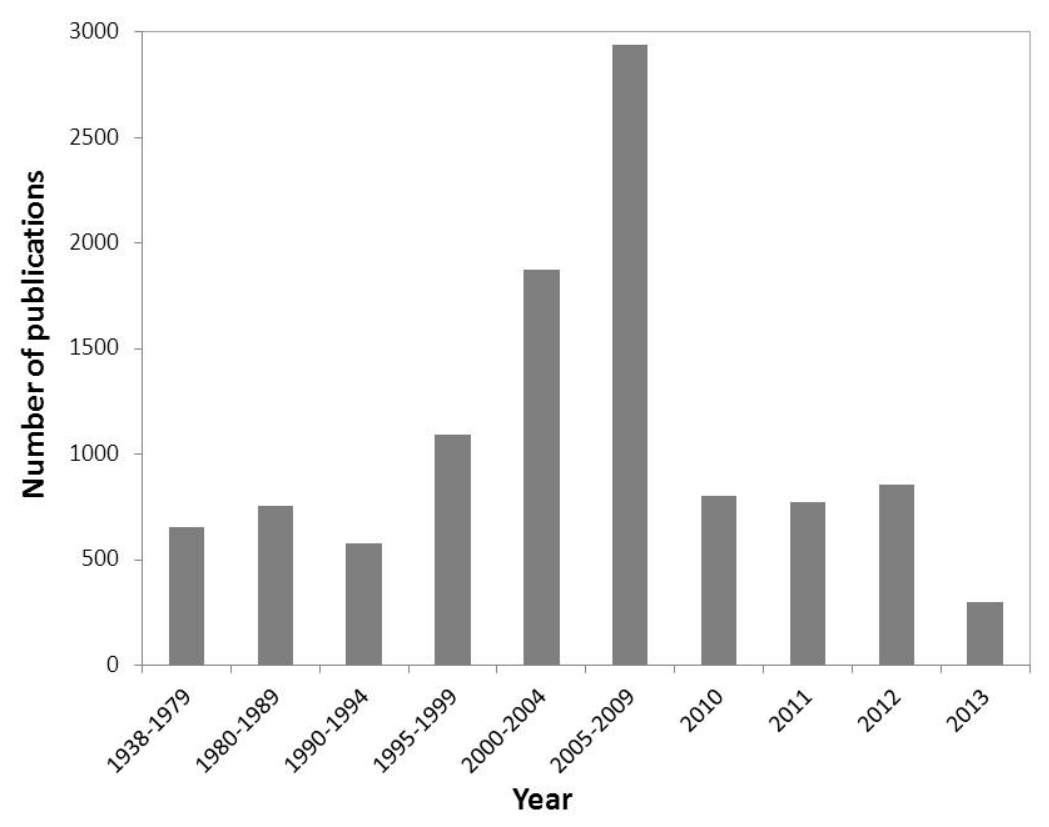

Figure 1. Number of publications for the topic of "clean fuels and Fischer-Tropsch" by searching Scifinder on May 15, 2013.

Within this issue of Energy \& Fuels, this special section highlights some of the papers presented in the symposium "Ultraclean Fuels Production and Utilization" at the $245^{\text {th }}$ ACS meeting in New Orleans, LA from April 7-11, 2013 in the Division of Energy and Fuels. This session covered a range of topics included synthesis of fuels from algae and Fischer-Tropsch, deep desulfurization, and denitrogenation. Recent progresses and further developments in the two most popular topics, i.e., deep desulfurization and the conversion of syngas to clean fuels including hydrocarbons, higher alcohols, and Dimethyl ether (DME), are highlighted based on the presentations and the referenced results.

\section{Deep desulfurization of petroleum feedstocks}


The hydrodesulfurization (HDS) of petroleum feedstocks at relatively higher temperatures (> $250{ }^{\circ} \mathrm{C}$ ) and pressures (> $2500 \mathrm{kPa}$ ) has been successfully industrialized as an effective technology for the removal of the low molecular sulfur-containing compounds such as sulfides and thiophenes. ${ }^{12-14}$ However, in order to meet present legal limits on transportation fuels in developed countries, i.e., $+99.99 \%$ of sulfur from a typical petroleum containing $1.5 \%$ sulfur, ${ }^{13}$ deep or ultra-deep desulfurization represents a major operational and economic challenge for the petroleum refining industry. To date, different strategies have been applied to meet the regulated sulfur levels, which are quantitatively reviewed in the recent references. ${ }^{13-17}$ Besides process considerations, ${ }^{14,}{ }^{18}$ studies on the development of more efficient HDS catalyst have still been very active in recent years, ${ }^{13}$ and the strong inhibiting effect of the N-containing heterocyclic compounds on HDS makes hydrodenitrogenation (HDN) a hot topic in achieving ultra-low sulfur transportation fuels. Alternatively, oxidative desulphurization (ODS) by using green oxidant $\mathrm{H}_{2} \mathrm{O}_{2}$ and novel methods based on photochemistry, ${ }^{16}$ electrochemistry, ${ }^{19}$ biochemistry, ${ }^{17}$ are also intensively investigated as important directions for ultra-deep desulfurization. During the symposium of "Ultraclean Fuels Production and Utilization”, all of these topics related to desulfurization were presented from the modification of the HDS catalyst ${ }^{20}$, the application of ionic liquids and magnetic nano-catalyst for ODS ${ }^{21-}$ ${ }^{23}$, to the replacement of molecular hydrogen with "in situ" hydrogen ${ }^{24}$. It cannot be denied that significant improvements in process engineering and deep understandings on catalytic science have been made for the ultra-deep desulfurization process. However, the statement in the 2006 review by Ito et al.," ${ }^{17}$ "the classical hydrotreating options and their offshoots still hold the field of transportation-fuel desulphurization” is still valid today. The best alternative process for deep desulfurization is not clear yet for ultraclean transportation fuels to be achieved in a more efficient, environmentally benign and affordable manner. The target of near-zero or zero sulfur, the increasingly poorer quality of feedstocks, and the economic factors are still great challenges for refineries.

\section{Ultraclean fuels from syngas conversion}

Syngas can be produced through the thermochemical gasification of coal, natural gas, biomass, petroleum residue, and even sewage sludge. When renewable biomass is used as a feedstock, sustainable 
production of synthetic fuels from syngas may be achieved with low net $\mathrm{CO}_{2}$ emissions. More importantly, the relative easier removal of impurities such as sulfur and nitrogen and versatile conversion pathways make syngas an increasingly important source for manufacturing clean fuels and chemicals. Production of syngas from various sources and its conversion to fuels and chemicals have attracted considerable attention, and significant progresses in both industrial and academic domains have been made in recent years. ${ }^{5-6,18,25-27}$ Among the possible routes for the conversion of syngas to fuels and chemicals, ${ }^{6}$ Fischer-Tropsch (FT) synthesis and syntheses of higher alcohols and dimethyl ether (DME) are closely pertinent to transportation fuels. Starting from the essential background information, the important findings presented in the symposium are highlighted as follows.

Being the key reaction of coal-to-liquids (CTL), gas-to-liquids (GTL), and biomass-to-liquids (BTL), FT synthesis can upgrade coal, natural gas and biomass via syngas into clean hydrocarbon fuels free of sulfur, nitrogen, and aromatics. Both CTL and GTL have been successfully commercialized. However, due to Anderson-Schulz-Flory (ASF) polymerization kinetics, the FT products are a complicated mixture of mostly normal paraffins with a wide range of carbon numbers, and are nonselective to any specific product. ${ }^{28}$ For the production of clean, high-quality gasoline or diesel fuels, downstream upgrading of the FT products, similar to petroleum, is required. Thus, the selectively onestep synthesis of targeted product such as gasoline via controlling the product distribution represents one of the recent developing trends for FT synthesis. ${ }^{28-29}$ In addition to the application of zeolites for this purpose, ${ }^{29}$ promising results for wax-free FT synthesis have been obtained by using montmorillonite derived materials and cobalt as catalysts, ${ }^{28,}{ }^{30-31}$ and the catalytic behavior of the alkaline activated montmorillonite for FT synthesis was presented in the symposium ${ }^{32}$.

In comparison with natural gas, a number of organic and inorganic impurities such as tar, $\mathrm{NH}_{3}$, and HCN are contained in the biomass-derived syngas, ${ }^{33}$ which is suspected to affect the performance of FT catalyst. When $\mathrm{NH}_{3}$ is concerned, it has been reported that the FT activity over CoRe/ $\mathrm{NiAl}_{2} \mathrm{O}_{4}$ is not affected by adding $4.2 \mathrm{ppm} \mathrm{NH}_{3}$ into syngas. ${ }^{33}$ On the contrary, as presented in the symposium, hundreds hours of time-on-stream results indicate that a significant detrimental effect on the FT activity of 
$\mathrm{Co} / \mathrm{Al}_{2} \mathrm{O}_{3}$ is observed even adding $10 \mathrm{ppm} \mathrm{NH}$ into syngas. In the case of product selectivity, the impact of $\mathrm{NH}_{3}$ is clearly dependent on its concentration ${ }^{34}$. This finding is very important for FT synthesis by using biomass derived syngas, which frequently contains a certain amount of impure $\mathrm{NH}_{3}$.

Carbon efficiency has also continuously been an important issue for FT synthesis. ${ }^{4}$ The relatively low $\mathrm{H}_{2} / \mathrm{CO}$ ratio for syngas derived from the gasification of coal and the higher $\mathrm{CO}_{2}$ selectivity of ironbased catalysts for FT synthesis make the CTL process have much lower carbon efficiency. The efficient hydrogenation of $\mathrm{CO}_{2}$ during FT synthesis is a goal for the production of hydrocarbon fuels. In this aspect, the effect of $\mathrm{CO}_{2} / \mathrm{CO}$ ratio in syngas on the $\mathrm{FT}$ performance of $\mathrm{K} / \mathrm{Fe}-\mathrm{Cu}-\mathrm{Al}$ catalysts was investigated, and high $\mathrm{CO}_{2} / \mathrm{CO}$ ratio was found to be favorable for the catalytic stability by inhibiting carbon deposition over the catalyst ${ }^{35}$. FT synthesis in a fixed-bed reactor has been quantitatively investigated in supercritical media, especially pentane and hexane. ${ }^{36}$ In comparison with conventional FT results, the catalytic activity and selectivity of long-chain hydrocarbons are increased as a result of the higher heat and mass transfer rates of the supercritical media. Following these general observations, a new process by using compressed or supercritical $\mathrm{CO}_{2}$ as a reaction medium was demonstrated for hightemperature $\left(350{ }^{\circ} \mathrm{C}\right.$ ) FT synthesis over Fe-Zn-K catalyst, and presented in the symposium ${ }^{37}$. In comparison with the results without $\mathrm{CO}_{2}$, enhanced $\mathrm{CO}$ conversion to liquid fuels, tunable product composition, delayed catalyst deactivation, decreased $\mathrm{CO}_{2}$ production, and $\mathrm{CH}_{4}$ selectivity are clearly observed, the extents of which are strongly dependent on the ratio of $\mathrm{CO}_{2}$ to syngas and pressure. Besides the possible recycling of the unreacted gases, the additional benefit of the new process lies in the easy separation of the FT products into light hydrocarbons, middle distillate, and wax by simply tuning the pressure. Thus, a higher carbon efficiency of CTL is expected if the new FT process is applied.

Higher alcohols can be promoted as alternative fuels or alternative fuel additives in transportation for reduction of greenhouse gas emissions and increased overall energy efficiency. ${ }^{38}$ Thus, the production of higher alcohols from syngas has been an important topic in $\mathrm{C}_{1}$ chemistry. In comparison with methanol synthesis, although the synthesis of higher alcohols is thermodynamically favored, the reaction rate and selectivity are low. ${ }^{6,38-39}$ Mechanistically, two types of active sites for the molecular and dissociative 
adsorption of CO and their synergetic behavior over the catalyst are required for the production of higher alcohols from syngas. ${ }^{38-39}$ This is a great challenge in catalyst design. By changing the preparation method of ZnZr oxides, a clear change of the higher alcohol selectivity from propanol to isobutanol was presented in the symposium ${ }^{40}$, which may shed some lights on the design of catalysts for selective synthesis of higher alcohols from syngas.

The last topic which cannot be neglected for the synthetic fuels is the directly one-step synthesis of DME from syngas. DME is nontoxic and does not produce particulates after burning. ${ }^{41}$ In comparison with methanol synthesis, the direct synthesis of DME from syngas is thermodynamically favorable and kinetically viable. As clearly reflected from the two presentations in the symposium by using different catalysts $^{42-43}$, the potential industrialization of one-step DME synthesis from syngas is technically feasible. The breakthroughs in catalyst technology will enable the replacement of DME for diesel fuel, prompting its implementation.

\section{Conclusions and Summary}

Dirtier feed stocks and higher environmental standards help drive the need for ultraclean fuel production. Though processes such as deep desulfurization, particularly of dibenzothiophenes, have proven challenging, recent advances in catalysis and process technologies have helped to improve process efficiency and drive down associated costs. Fischer-Tropsch conversion of fuels is attractive due to the recent decrease in natural gas prices and the relative ease of cleaning the syn gas stream, though the production of high quality gasoline and diesel fuel without large amounts of down-stream upgrading remains a challenge. However, these advances with use of alternative feed stocks, such as algae and other biomass, will enable the development of cleaner, more sustainable transportation fuels.

\section{Acknowledgements}

The authors wish to thank The ACS Division of Energy and Fuels and Program Chairs Yun Hang Hu and Todd H. Gardner for their support on this effort. Dr. Elise Fox is an employee of Savannah River 
National Laboratory, which is managed by Savannah River Nuclear Solutions. Her portion of this work was prepared under Federal Contract DE-AC09-08SR22470. The United States Government retains, and by accepting the article for publication the publisher acknowledges that the United States Government retains, a non-exclusive, paid-up, irrevocable, worldwide license to publish or reproduce the published form of this work, or allow others to do so, for United States Government purposes.

\section{References}

1. Agency, U. S. E. P., Fuels and fuel additives. http://www.epa.gov/otaq/index.htm.

2. Song, C. S., Fuel processing for low-temperature and high-temperature fuel cells - challenges and opportunities for sustainable development in the 21st century. Catal. Today 2002, 77 (1-2), 17-49.

3. Huber, G. W.; Iborra, S.; Corma, A., Chem. Rev. 2006, 106, 4044-4098.

4. Liu, G.; Larson, E. D.; Williams, R. H.; Kreutz, T. G.; Guo, X., Energy Fuels 2011, 25, 415-437.

5. Street, J.; Yu, F., Biofuels 2011, 677-691.

6. Wender, I., Fuel Process. Tech. 1996, 46, 189-297.

7. Silk, M.; Ackiewicz, M.; Anderson, J.; Ogunsola, O., Overview of fundamentals of synthetic ultraclean transportation fuel production. In Ultraclean transportation fuels, American Chemical Society: 2007; Vol. 959, pp 3-17.

8. Annual energy outlook 2013 with projections to 2040. DOE/EIA-03803(2013) 2013, U.S. Energy Information Administration.

9. $\quad$ http://www.eia.gov/naturalgas/crudeoilreserves/index.cfm.

10. Agency, U. S. E. P. Our nation's air- status and trends through 2008; U.S. E.P.A. Office of Air Quality Planning and Standards: Research Triangle Park, NC, February 2010, 2010.

11. Agency, U. S. E. P. Inventory of u.S. Greenhouse gas emissions and sinks: 1990-2010; U.S. E.P.A.: Washington, D.C., April 15, 2012, 2012.

12. Staiger, C. L.; Loy, D. A.; Jamison, G. M.; Schneider, D. A.; Cornelius, C. J., J. Am. Chem. Soc. 2003, 125 (9920-9921).

13. Oyama, S. T.; Gott, T.; Zhao, H.; Lee, Y.-K., Catal. Today 2009, 143, 94-107.

14. Stanislaus, A.; Marafi, A.; Rana, M. S., Catal. Today 2010, 153, 1-68.

15. Shang, H.; Du, W.; Liu, Z.; Zhang, H., J. Ind. Eng. Chem. 2013, 19 (1061-1068).

16. Samokhvalova, A., Catal. Rev.- Sci. Tech 2012, 54, 281-343.

17. Ito, E.; Van Veen, J. A. R., Catal. Today 2006, 116, 446-460.

18. Jia, J.; Yu, B.; Measen, T.; Radlowski, C.; Dahlberg, A.; Creighton, J.; Krenzke, D.; Torchia, S.; Shifltt, W., Chin. J. Catal. 2009, (836-838).

19. Lam, V.; Li, G.; Song, C.; Chen, J.; Fairbridge, C.; Hui, R.; Zhang, J., J. Fuel Process. Technol. 2012, 98, 30-38.

20. Al-Dalama, K.; Navvamani, R., Effect of edta on the reducability of como catalyst supported on $\mathrm{al}_{2} \mathrm{O}_{3}$ and $\mathrm{siO}_{2}-\mathrm{al}_{2} \mathrm{O}_{3}$. Prepr. - Am. Chem. Soc., Div. Energy Fuels 2013, 58 (1), 1026.

21. Dupont, J., On the oxidative desulfurization of fules catalyzed by iron-ionic tagged bipyridine or task-specific salts in imidazolium ionic liquids. Prepr. - Am. Chem. Soc., Div. Energy Fuels 2013, 58 (1), 1027.

22. Siddiqui, M. N.; Alhooshani, K. R.; Gondal, M. R.; Ranu, B. C., Desulfurization of model fuel using novel ionic liquids. Prepr. - Am. Chem. Soc., Div. Energy Fuels 2013, 58 (1), 1022-1023. 
23. Liu, P.; Cui, X.; Hu, D., Magnetic nanoparticles surfacely loaded phase transfer catalyst used in catalytic oxidation of dibenzothiophene. Prepr. - Am. Chem. Soc., Div. Energy Fuels 2013, 58 (1), 10201021.

24. Liu, K.; Jia, L.; Ng, F. T. T., Hydrogenation of carbazole over dispersed mo sulfide catalyst using in situ $\mathrm{h}_{2}$. Prepr. - Am. Chem. Soc., Div. Energy Fuels 2013, 58 (1), 1055.

25. Baliaban, R. C.; Elia, J. A.; Floudas, C. A.; Gurau, B.; Weingarten, M. B.; Klotz, S. D., Energy Fuels 2013, ASAP, 10.1021/ef302003f.

26. Zhang, W., Fuel Process. Tech. 2010, 91, 866-876.

27. Nzihou, A.; Flamant, G.; Stanmore, B., Energy 2012, 42, 121-131.

28. Hao, Q.-Q.; Wang, G.-W.; Liu, Z.-T.; Lu, J.; Liu, Z.-W., Ind. Eng. Chem. Res. 2010, 49, 9004-9011.

29. Zhang, Q.; Kang, J.; Wang, Y., ChemCatChem 2010, 2, 1030-1058.

30. Wang, G.-W.; Hao, Q.-Q.; Liu, Z.-T.; Liu, Z.-W., Appl. Catal. A: Gen. 2011, 405, 45-54.

31. Hao, Q.-Q.; Liu, Z.-W.; Zhang, B.; Wang, G.-W.; Ma, C.; Frandsen, W.; Li, J.; Liu, Z.-T.; Hao.Z.; Su, D., Chem. Mater. 2012, 972-974.

32. Zhao, Y.-H.; Hao, Q.-Q.; Liu, Z.-T.; Liu, Z.-W., Montmorillonite activated with potassium hydroxide for fischer-tropsch synthesis over cobalt. Prepr. - Am. Chem. Soc., Div. Energy Fuels 2013, 58 (1), 1030.

33. Borg, Ø.; Hammer, N.; Enger, B. C.; Myrstad, R.; Lindvåg, O. A.; Eri, S.; Skagseth, T. H.; Rytter, E., J. Catal. 2011, 279, 163-173.

34. Pendyala, V. R. R.; Gnanamani, M. K.; Ma, W.; Jacobs, G.; Shafer, W. D.; Davis, B. H., Fischertropsch synthesis: Effect of ammonia impurities in syngas feed over cobalt catalyst. Prepr. - Am. Chem. Soc., Div. Energy Fuels 2013, 58 (1), 1041-1042.

35. Kang, S. C.; Lee, Y.-J.; Jun, K.-W., Effects of $\mathrm{co} / \mathrm{CO}_{2}$ ratio in synthesis gas on catalytic behaviors in fisher-tropsch synthesis using k/fe-cu-al catalysts. Prepr. - Am. Chem. Soc., Div. Energy Fuels 2013, 58 (1), 1040.

36. Abbaslou, R. M. M.; Mohammadzadeh, J. S. S.; Dalai, A. K., Fuel Process. Tech. 2009, 90, 849-856.

37. Carron, D.; Sims, A.; Gautam, J.; Soti, M.; Perry, D.; Benoit, J.; Mondal, K., Fischer tropsch synthesis in compressed $\mathrm{CO}_{2}$. Prepr. - Am. Chem. Soc., Div. Energy Fuels 2013, 58 (1), 1038-1039.

38. Surisettya, V. R.; Dalaia, A. K.; Kozinskib, J., Appl. Catal. A: Gen. 2011, 404, 1-11.

39. Subramani, V.; Gangwal, S. K., Energy Fuels 2008, 22, 814-839.

40. Kou, Y.; Xie, H.; Wu, Y.; Han, Y.; Tan, Y., Effect of preparation methods on zncr based catalyst for isobutanol synthesis from syngas Prepr. - Am. Chem. Soc., Div. Energy Fuels 2013, 58 (1), 1053-1054.

41. Mao, D.; Yang, W.; Xia, J.; Zhang, B.; Song, Q.; Chen, Q., J. Catal. 2005, 230, 140-149.

42. Song, F.; Tan, Y.; Xie, H.; Zhang, Q.; Han, Y., Effect of zr modification to cu-zno-al ${ }_{2} \mathrm{O}_{3} / \mathrm{hszm}-5$ on catalytic performance for direct synthesis of dimethyl ether from biomass-derived syngas. Prepr. - Am. Chem. Soc., Div. Energy Fuels 2013, 58 (1), 1043-1045.

43. Takeishi, K., Direct synthesis of dimethyl ether from syngas over copper catalyst prepared using the sol-gel method. Prepr. - Am. Chem. Soc., Div. Energy Fuels 2013, 58 (1), 1018-1019. 